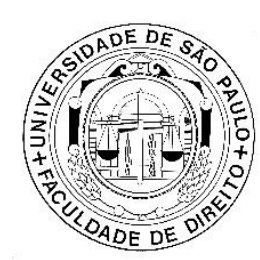

MARCOS ROBERTO FRANCO

\title{
A FLEXIBILIZAÇÃO DO PRINCÍPIO DA SUPREMACIA DO INTERESSE PÚBLICO DIANTE DA DEMOCRACIA PARTICIPATIVA
}

\author{
Tese de Doutorado \\ Orientador: Professor Associado Dr. Edmir Netto de Araújo
}

Universidade de São Paulo

Faculdade de Direito

São Paulo - SP

2018 
Catalogação da Publicação

Serviço de Biblioteca e Documentação

Faculdade de Direito da Universidade de São Paulo

Franco, Marcos Roberto

A Flexibilização do Princípio da Supremacia do Interesse Público Diante da

Democracia Participativa / Marcos Roberto Franco ; orientador Edmir Netto

de Araújo -- São Paulo, 2018.

$171 \mathrm{p}$.

Tese (Doutorado - Programa de Pós-Graduação em Direito do Estado) Faculdade de Direito, Universidade de São Paulo, 2018.

1. Interesse Público. 2. Supremacia. 3. Democracia participativa. 4. processualização. I. Araújo, Edmir Netto de, orient. II. Título. 


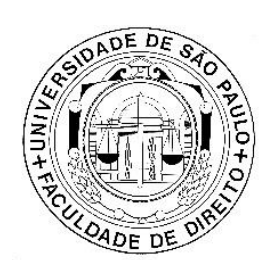

MARCOS ROBERTO FRANCO

\section{A FLEXIBILIZAÇÃO DO PRINCÍPIO DA SUPREMACIA DO INTERESSE PÚBLICO DIANTE DA DEMOCRACIA PARTICIPATIVA}

Tese apresentada a Banca Examinadora do Programa de Pós-Graduação em Direito, da Faculdade de Direito da Universidade de São Paulo, como exigência parcial para obtenção do título de Doutor em Direito, na área de Concentração Direito do Estado, sob a orientação do Professor Associado Doutor Edmir Netto de Araújo.

\section{Universidade de São Paulo}

Faculdade de Direito

São Paulo - SP

2018 

MARCOS ROBERTO FRANCO

\section{A FLEXIBILIZAÇÃO DO PRINCÍPIO DA SUPREMACIA DO INTERESSE PÚBLICO DIANTE DA DEMOCRACIA PARTICIPATIVA}

BANCA EXAMINADORA:

Prof. Associado Dr. Edmir Neto de Araújo FDUSP

FDUSP

FDUSP

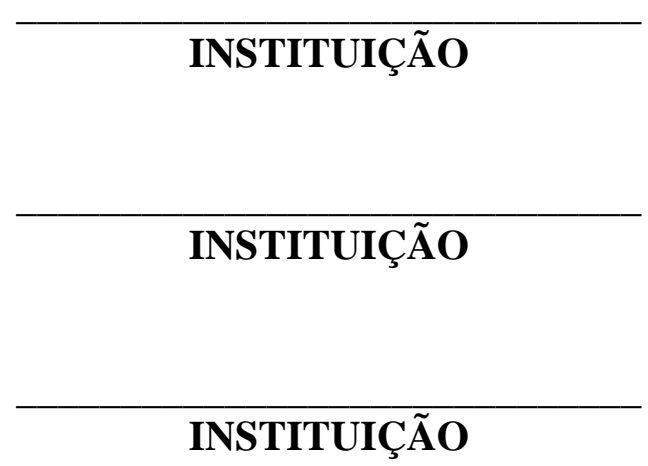

Aprovado em: 



\section{AGRADECIMENTOS:}

Agradeço primeiramente a Deus que é o propiciador de todas as coisas - Tudo é graça.

Agradeço ao Professor Dr. Edmir Netto de Araújo pela orientação, pelos conselhos, pelas histórias e, em especial, pela amizade que carregarei comigo por toda vida.

Agradeço aos colegas Procuradores do Município de São Paulo, em especial os que trabalham comigo na Secretaria de Governo do Município. O incentivo e a compreensão de vocês contribuíram de forma decisiva para que eu pudesse perseverar nos momentos mais difíceis e chegar até este ponto.

Agradeço à minha esposa Juliana, e aos meus filhos, Marcos e Giovanna, que souberam compreender este momento e me incentivar nesta jornada. Vocês são a minha inspiração. 

RESUMO: A presente pesquisa tem como objetivo demonstrar que a evolução do Estado Democrático e a influência da Democracia Participativa produziram a flexibilização do Princípio da Supremacia do Interesse Público, porém, sem desconstruir sua validade, importância e, em especial, sua principal característica, a preponderância sobre os interesses privados. Após um breve histórico do instituto e de ressaltar suas principais características para doutrina brasileira, entre as quais a de ser reconhecido como princípio basilar do Direito Administrativo, informamos que o instituto foi contestado por parte da doutrina que passou a considerá-lo incompatível a com a atual proteção dada pela Constituição aos direitos e garantias individuais. Reportamos que a doutrina clássica reagiu fortemente a este pensamento, reafirmando a importância e a validade do princípio. Também procuramos demonstrar entre outros pontos, como o instituto se modernizou, tornando-se compatível com o Estado pósmoderno por meio da exigência da legitimação dos atos da Administração, sem deixar de ser prevalente, especialmente nos casos relativos à formação de políticas públicas e nos atos de grande impacto na vida dos cidadãos. Por fim, procuramos demonstrar a importância do processo como mecanismo eficaz para apuração da vontade do cidadão.

ABSTRACT: This research aims to demonstrate that the evolution of the Democratic State and the influence of the Participative Democracy produced the flexibilization of the Principle of Public Interest Supremacy, however without deconstructing its validity, importance and, in particular, its main characteristic, the preponderance over private interests. After a brief history of the institute and highlighting its main characteristics for the Brazilian doctrine, among which being recognized as a basic principle of the Administrative Law, we showed that the institute was contested by part of doctrine that considers it incompatible with the current protection given by the Constitution to individual rights and guarantees. We also report that the classical doctrine strongly reacted to this thought, reaffirming the importance and validity of the principle. We also sought to demonstrate, among other points, how the institute modernized itself, becoming compatible with the postmodern State, by requiring the legitimization of the acts of the Administration, without ceasing to be prevalent, especially in cases related to the formation of public policies and in acts of great impact on citizens' lives. Finally we present the importance of the process as a mechanism for effective determination of the citizen's will. 
SOMMARIO: Questa ricerca mira a dimostrare che l'evoluzione dello Stato democratico e l'influenza della Democrazia Partecipativa ha prodotto la flessibilizzazione del principio di supremazia di interesse pubblico, ma senza decostruire la sua validità, l'importanza e, in particolare, la sua caratteristica principale, la preponderanza sugli interessi privati. Dopo una breve presentacione della storia dell'Istituto e per sottolineare le sue caratteristiche principali per la dottrina brasiliana, tra cui quello di essere riconosciuto come un principio fondamentale del diritto amministrativo, informiamo che l'istituto è stato contestato per una parte di dottrina che lo considera incompatibile con l'attuale protezione data dalla Costituzione ai diritti e alle garanzie individuali. Segnaliamo che la dottrina classica ha reagito con forza a questo pensiero, riaffermando l'importanza e la validità del principio.Abbiamo anche dimostrato, tra l'altro, come l'istituto si è modernizzato, diventando compatibile con lo stato postmoderno richiedendo la legittimazione degli atti dell'Amministrazione senza cessare di essere prevalente, specialmente nei casi legati alla formazione di politiche pubbliche e in atti di grande impatto sulla vita dei cittadini. Infine, cerchiamo di dimostrare l'importanza del processo come un meccanismo efficace per determinare la volontà del cittadino. 


\section{A FLEXIBILIZAÇÃO DO PRINCÍPIO DA SUPREMACIA DO INTERESSE PÚBLICO DIANTE DA DEMOCRACIA PARTICIPATIVA}

\section{SUMÁRIO:}

I - INTRODUÇÃO .13

II - NOÇÕES GERAIS SOBRE O TEMA ……................................... 17

III - A SUPREMACIA DO INTERESSE PÚBLICO E O ATUAL

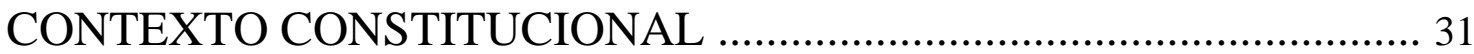

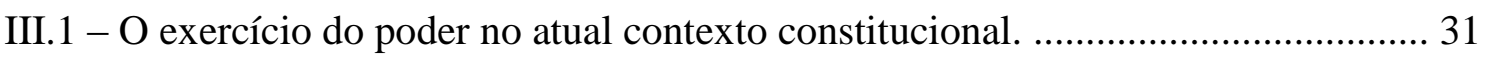

III.2- A dialética em torno do princípio da supremacia do interesse público. ............... 39

III.2.1 - O posicionamento da doutrina contrária à manutenção da supremacia do

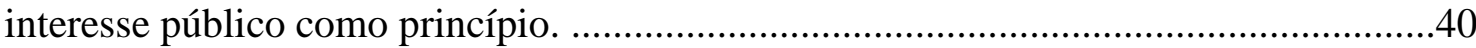

III.2.2 - A reação às críticas ao princípio da supremacia do interesse público. ............. 47

III.3 - Estado, pós-modernidade e supremacia do interesse público.

III.4 - A inevitabilidade do uso do princípio da supremacia do interesse público pelo

Estado.

IV - DEMOCRACIA PARTICIPATIVA E A SATISFAÇÃO DO

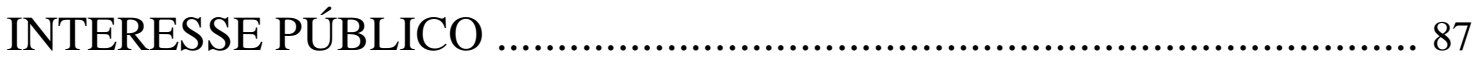

IV.1- Democracia participativa e legitimação do interesse público.............................. 87

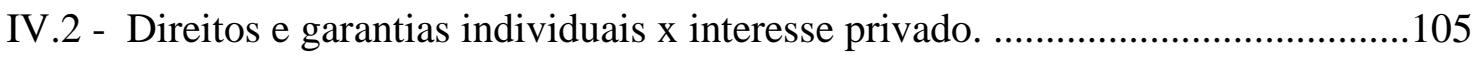

IV.3 - A flexibilização do princípio da supremacia do interesse público.....................118

IV.4 - A implementação do interesse público por meio de políticas públicas

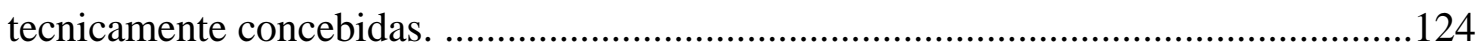

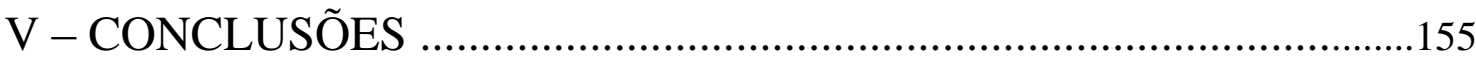

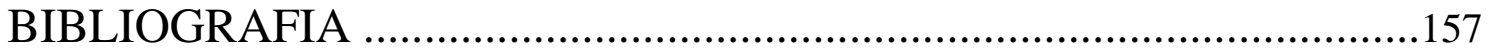





\section{I - INTRODUÇÃO:}

Um dos princípios mais basilares do Direito Administrativo, no qual se apoiam, em especial, os atos de governança e de força do Poder Público (puissance publique) é o denominado "Princípio da Supremacia do Interesse Público". Basta uma rápida consulta aos manuais dos mais renomados administrativistas pátrios ou estrangeiros para constatarmos que tal princípio se confunde com a própria ideia de Estado $^{1}$ que, agindo em nome do interesse geral, manifestado por meio das leis, faz valer seu poder/dever de agir em detrimento do interesse individual que porventura se contraponha àquele.

Escorado nesta ideia-força, até há pouco tempo quase inconteste, o Estado, mormente pela ação do Poder Executivo, implementa políticas públicas, fiscaliza posturas, aplica sanções, exige comportamentos, regula atividades, estabelece e cobra impostos, enfim, faz preponderar o interesse que, presumidamente, é a manifestação do interesse público predominante.

Um princípio tão fundamental e arraigado, que sustenta todas as áreas do Direito Público ${ }^{2}$, que embasa todas as disciplinas deste ramo do Direito $^{3}$, e que alguns denominam, inclusive, como "primado do interesse público"4, traduz-se numa manifestação de poder tão cogente, numa presunção de tão grande abrangência - a de que o Estado age com supremacia por agir em nome do interesse público - que, por si só, faz sobressair sua importância doutrinária, não podendo, por isto mesmo, escapar de constantes reexames, ponderações e questionamentos.

Trata-se, portanto, de um tema sempre atual e relevante ${ }^{5}$, pois, sendo o Estado um fenômeno dinâmico em suas mais variadas manifestações na história, desafia o estudioso do Direito a constantemente investigar seus mecanismos de atuação, na busca do desejado equilíbrio entre a operacionalidade e a eficiência que dele

\footnotetext{
${ }^{1}$ V.g. ARAÚJO, Edmir Netto de. Curso de Direito Administrativo, $7^{\mathrm{a}}$ ed., São Paulo: Saraiva, 2016, p. 71.

${ }^{2}$ NOHARA, Irene Patrícia, Direito Administrativo, 2a ed., São Paulo: Atlas, 2012, p. 56.

${ }^{3}$ NOHARA. Irene Patrícia. Reflexões críticas acerca da tentativa de desconstrução do sentido da supremacia do interesse público no Direito Administrativo. In : Supremacia do interesse público e outros temas relevantes do direito administrativo, DI PIETRO, Maria Sylvia Zanella. RIBEIRO, Carlos Vinícius Alves (coordenadores), Ed. Atlas, São Paulo, 2010, p. 130.

${ }^{4}$ ARAÚJO, Edmir Netto de .Op. cit., p. 72.

5 Neste sentido: ARANA MUÑOS, Jaime Rodriguez. in: BACELLAR FILHO, Romeu Felipe; HACHEM, Daniel Wunder. (coords.). Direito Administrativo e Interesse Público: Estudos em Homenagem ao Professor Celso Antônio Bandeira de Mello. Belo Horizonte: Editora Fórum, 2010, p. 33.
} 
se espera e, ao mesmo tempo, a garantia da preservação dos demais interesses da sociedade, desde a esfera pessoal até as mais novas manifestações de interesses, tais como os direitos coletivos, difusos, meta-individuais, de preservação do meio ambiente, do consumidor, apenas para citar alguns dos novos grupos de motivação que, hodiernamente, podem se contrapor à manifestação da denominada supremacia do interesse público.

Daí a importância não apenas teórica, mas também prática, do estudo criterioso deste princípio.

Ocorre que, não obstante os elementos acima apontados, tem surgido, já de algum tempo, uma marcante discussão a respeito da manutenção desta supremacia do interesse público frente aos modernos mecanismos de proteção aos direitos individuais e garantias constitucionais, com ênfase à prevalência destes. Levantam-se vozes e teorias para defender a relativização do princípio da supremacia do interesse público e, até, para a afirmar que tal instituto não tem mais lugar no contemporâneo Estado Democrático de Direito ${ }^{6}$.

Atentos à importância do tema e às implicações trazidas por esta (contestante) corrente do pensamento jurídico, nos propusemos aqui a explorar e investigar este fenômeno (a relativização ou superação do princípio da supremacia do interesse público), com o fim repensar o princípio, testando sua higidez, na busca por descobrir sua eventual nova roupagem frente às novas tendências do Direito e aos modernos mecanismos de participação, controle popular e de legitimação das ações da Administração Pública, pois acreditamos que esteja, aí, a chave para solução deste aparente conflito de ideias.

Por meio de uma minuciosa pesquisa, que alcançará desde as origens do instituto até as mais recentes ponderações sobre a problemática de sua aplicação, procuraremos discutir, do ponto de vista eminentemente teórico, a prevalência ou não da ação do Estado baseado na supremacia interesse público; os paradigmas para aplicação do princípio; as implicações para o Estado, para a coletividade e para o cidadão do uso da potestade estatal; se o uso deste princípio é discricionário; os limites toleráveis de ponderação entre o interesse público e os direitos fundamentais do indivíduo ou de grupos de indivíduos; o momento adequado para

\footnotetext{
${ }^{6}$ Alguns dos textos mais relevantes neste sentido foram reunidos na obra: Interesses Públicos versus Interesses Privados: Desconstruindo o princípio da supremacia do interesse público. SARMENTO, Daniel. (org.). Rio de Janeiro: Ed. Lúmen Júris, 2007.
} 
ponderação; o conteúdo ou elementos ponderáveis; o alcance da expressão interesse público; a composição deste interesse em tempos de formação de políticas, por meio da participação popular; os mecanismos de conformação do interesse público, entre outros temas percucientes.

O elenco das hipóteses preliminares de estudo, a abrangência do tema e a repercussão da efetiva atuação do Estado, por meio de sua supremacia num contexto que propicie a participação dos cidadãos, são motivos mais do que justificadores para uma pesquisa que buscará respostas para algumas questões inquietantes e fundamentais, que põem em dúvida a própria solidez do instituto, mas que, a nosso ver, abrem espaço para uma nova perspectiva de abordagem do tema.

O trabalho não se limitará, porém, a simplesmente se posicionar contra ou a favor do instituto, abraçando esta ou aquela hipótese por razões ideológicas, teóricas ou empíricas. A pesquisa buscará esmiuçar o tema, medindo, de modo científico, as consequências da relativização ou mitigação do princípio para a governabilidade e para a efetiva consecução dos fins a que o Estado se destina, procurando descobrir se esta tendência desconstrutiva realmente resiste a uma análise mais profunda, nas palavras de Luís Roberto Barroso: "testando a consistência das ideias dominantes ${ }^{7}$.

\footnotetext{
7 BARROSO, Luís Roberto. "O Estado Contemporâneo, os Direitos Fundamentais e a Redefinição da Supremacia do Interesse Público". Prefácio da obra: Interesses Públicos versus Interesses Privados: Desconstruindo o princípio da supremacia do interesse público. (org.) SARMENTO, Daniel. Rio de Janeiro: Ed. Lúmen Júris, 2005, p. ix.
} 


\section{V - CONCLUSÕES}

Conforme procuramos demonstrar durante a exposição de nossa pesquisa, o princípio da supremacia do interesse público continua sendo um dos principais pilares do Direito Público, em especial do Direito Administrativo. Acompanhando todo avanço experimentado por este dinâmico ramo da ciência jurídica, constatamos que o princípio que estabelece a prevalência do interesse público sobre o particular também evoluiu, incorporando novos elementos democráticos em sua composição essencial, preservando, porém, a sua relevância, especialmente porque se mantém útil e necessário para o estabelecimento de uma sociedade mais justa e igualitária.

Pudemos demonstrar que, deixando para trás o viés autoritário e auto justificante de outras épocas, o instituto modernizou-se, superando o seu caráter impositivo e vertical, baseado em uma autoridade quase mítica, para se impor como instrumento de busca pelo bem-estar de todos, conforme objetivo fixado pelo artigo $3^{\circ}$, inciso IV da Constituição Federal, onde se encontra matizado.

A despeito das críticas que lhe foram dirigidas, conforme pudemos retratar, o princípio manteve-se hígido, em nada conflitando com a proteção constitucional às garantias individuais. Isto porque, conforme nos esforçamos em comprovar, somente por meio da implementação do interesse público legítimo é possível garantir, a todos, de modo isonômico, a fruição dos direitos individuais não egoísticos. Nesta senda, pudemos ponderar qual a natureza real deste direito individual que a sociedade pós-moderna protege, qual seja, um interesse de um cidadão que se reconhece inserido na sociedade, e que é consciente desta sua dimensão. ${ }^{510}$

Apontamos ainda que, para manutenção de uma sociedade solidária, é imprescindível que o Estado, cada vez mais demandado, tenha condições de impor o interesse público quando necessário, muitas vezes contra a vontade do indivíduo ou de um grupo. Pudemos registrar que, sem esta prerrogativa, o Estado jamais conseguiria cumprir seu objetivo maior de implantar um ambiente de mínima condição de convivência equilíbrio social, pois, dificilmente, o indivíduo abriria mão de seus direitos em prol do coletivo.

Mas, em especial, procuramos comprovar - e este é o núcleo de nossa tese - que o princípio da supremacia do interesse público mantem-se

510 Conforme conceito defendido Celso Antônio Bandeiro de Mello in: BANDEIRA DE MELLO. Grandes Temas de Direito Administrativo. São Paulo: Malheiros, 2009, p. 183 
relevante porque se flexibilizou, deixando-se irrigar pelos novos paradigmas do Estado social de direito participativo, no qual o interesse público permanece prevalente.

A pesquisa demonstra, também, de que modo esta supremacia deve ser consubstanciada e construída no ambiente de democracia participativa. Indicamos que é por meio da elaboração de políticas públicas tecnicamente bem concebidas e permeadas pela vontade legitimante do cidadão consciente que o Estado, de fato, encontra caminhos para impor, quando necessário, o interesse público.

Apresentamos, em complemento, as razões pelas quais acreditamos que, somente pela previsão legal de procedimentos em que a participação popular é garantida, o Estado poderá aquilatar com maior eficiência qual é o real interesse público a ser implementado. Destacamos que a procedimentalização da formação das políticas públicas e das ações de grande impacto da Administração não implicam em burocratização, morosidade ou perda de eficiência, mas, ao contrário, apresenta-se como fator que contribui para a implementação da democracia participativa. Defendemos, escorados nas lições de renomados autores, que é por meio do processo que se conseguirá reduzir os conflitos de interesse e melhorar a aceitação das ações que o Estado precisa implementar, muitas vezes de forma impositiva.

É certo que ainda há um longo caminho a se trilhar em termos de busca por um interesse público realmente legitimado. É preciso trabalhar pela edição de um corpo normativo que preveja, nas várias esferas de governo, procedimentos com a participação dos cidadãos nas decisões administrativas de relevância. Tais procedimentos, por outro lado, se tornarão cada vez mais dinâmicos e efetivos, na medida em que avançarem os esforços para a implementação de uma governança mais ágil, que utilize recursos eletrônicos (processos administrativos eletrônicos, meios eletrônicos de capitação de opinião, etc,), fazendo com que, tanto a publicidade dos atos, quanto a própria participação e o controle de resultados, sejam viáveis e eficazes.

Enquanto não atingimos tal nível de governança, é preciso que todos estejamos atentos quanto a esta nova forma de interpretar o interesse público, flexibilizado, mas prevalente, uma vez que democratizado e informado pela vontade legitimante do cidadão que o reposiciona como mecanismo adequado para a busca do bem de todos. 


\section{- BIBLIOGRAFIA:}

- ALESSI, Renato. Principi di diritto ammistrativo: i soggeti attivi e l'esplicazione dela funzione ammistrativa. $4^{\mathrm{a}}$ ed. Milano: Giuffrè, 1978. T. 1.

- ALEXY, Robert. Conceito e Validade do Direito. Tradução Gercélia Batista de Oliveira Mendes. São Paulo: Martins Fontes, 2011.

. Colisão de direito fundamentais e realização de direitos fundamentais no Estado de Direito democrático. Revista de Direito Administrativo, Rio de Janeiro, v. 217, p. 67-79, mar. 2015. ISSN 2238-5177. Disponível em: <http://bibliotecadigital.fgv.br/ojs/index.php/rda/article/view/47414>. Acesso em: 14 Mar. 2017. doi:http://dx.doi.org/10.12660/rda.v217.1999.47414.

- Teoria de los derechos fundamentales. Madrid: Centro de Estúdios Constucionales, 1993.

- AlMEIDA, Fernando Dias Menezes de. Mecanismos de consenso no Direito administrativo. In: ARAGÃO, Alexandre Santos de; MARQUES NETO, Floriano de Azevedo (Coord.). Direito administrativo e seus novos paradigmas. $2^{\mathrm{a}}$ ed. Belo Horizonte: Fórum, 2017. p. 325-336.

- AMARAL, Diogo Freitas do. Curso de Direito Administrativo, $2^{a}$ ed., vol III. São Paulo: Ed. Almedina, 2014.

- ARAGÃO. Alexandre Santos de. “A ‘Supremacia do Interesse Público’ no advento do Estado de Direito e na Hermenêutica do Direito Público Contemporâneo" In: Interesses Públicos versus Interesses Privados: Desconstruindo o princípio da supremacia do interesse público. SARMENTO, Daniel (org.). Rio de Janeiro: Ed. Lúmen Júris, 2005. pp. 1-22.

- ARANA MUÑOZ, Jaime Rodriguez. In: BACELLAR FILHO, Romeu Felipe; HACHEM, Daniel Wunder. (coords.). Direito Administrativo e Interesse Público: 
Estudos em Homenagem ao Professor Celso Antônio Bandeira de Mello. Belo Horizonte: Editora Fórum, 2010.

- ARAÚJO, Edmir Netto de. Curso de Direito Administrativo. $7^{a}$ ed. São Paulo: Saraiva, 2016.

- ÁVILA, Humberto. "Repensando o princípio da supremacia do interesse público sobre o interesse particular", In: Interesses Públicos versus Interesses Privados: Desconstruindo o princípio da supremacia do interesse público. (org.) SARMENTO, Daniel, Rio de Janeiro: Ed. Lúmen Júris, 2007.

- BACELLAR FILHO, Romeu Felipe. A noção jurídica de interesse público no Direito administrativo brasileiro. In: BACELLAR FILHO, Romeu Felipe; HACHEM, Daniel Wunder. (coords.). Direito Administrativo e Interesse Público: Estudos em Homenagem ao Professor Celso Antônio Bandeira de Mello. Belo Horizonte: Editora Fórum, 2010

- BANDEIRA DE MELlO, Celso Antônio. Curso de Direito Administrativo. $21^{\mathrm{a}}$ ed. São Paulo: Malheiros, 2006.

Grandes Temas de Direito Administrativo. São Paulo: Malheiros, 2009.

- BAPTISTA, Patrícia. Transformações do direito administrativo. Rio de Janeiro: Renovar, 2003.

- BARROSO, Luís Roberto. “O Estado Contemporâneo, os Direitos Fundamentais e a Redefinição da Supremacia do Interesse Público”. Prefácio da obra: Interesses Públicos versus Interesses Privados: Desconstruindo o princípio da supremacia do interesse público. SARMENTO, Daniel (org.). Rio de Janeiro: Ed. Lúmen Júris, 2007.

Interpretação e aplicação da constituição - Fundamentos de uma dogmática constitucional transformadora. $6^{\text {a }}$ ed. São Paulo: Saraiva, 2008. 
- BINEMBOJM, Gustavo. Da Supremacia do Interesse Público ao Dever de Proporcionalidade: um novo paradigma para o Direito Administrativo. In: SARMENTO, Daniel (org.). Interesses públicos versus Interesses privados: desconstruindo o princípio de supremacia do interesse público. Rio de Janeiro: Lumen Juris, 2005, ou em: http://www.mundojuridico.adv.br

- Uma teoria do direito administrativo: direitos fundamentais, democracia e constitucionalização. $2^{\mathrm{a}}$ ed. Rio de Janeiro: Renovar, 2008.

- BOBBIO, Norberto. O Futuro da Democracia - Uma defesa das regras do jogo. Trad. Marco Aurélio Nogueira. 14a edição. Rio de Janeiro/São Paulo: Paz e Terra, 2017.

- BONAVIDES, Paulo. Teoria Constitucional da Democracia Participativa. $3^{\text {a }}$ ed. São Paulo: Malheiros Editores, 2008.

Teoria Geral do Estado. Malheiros Editores. 10ª ed. São Paulo, 2015.

- BORGES, Alice Gonzalez. Supremacia do Interesse Público: desconstrução ou reconstrução? Revista Diálogo Jurídico, Salvador, nº 15, jan./fev./mar. 2007. Disponível em: <http://files.direitoeticaedignidade.webnode.com.br/200000234> Acesso em $11 / 10 / 2016$.

- BUCCI, Maria Paula Dallari Fundamentos para uma Teoria Jurídica das Políticas Públicas. São Paulo: Saraiva, 2013.

(org.). Políticas Públicas: reflexões sobre o conceito jurídico. São Paulo: Saraiva, 2006.

- CANOTILHO, JJ Gomes. Constitucionalismo e geologia da good governance. In: "Brancosos" e interconstitucionalidade: itinerários dos discursos sobre a historicidade constitucional. Coimbra: Almedina, 2006. 
- CARVALHO FILHO. José dos Santos. Interesse Público: Verdades e Sofismas. In : Supremacia do interesse público e outros temas relevantes do direito administrativo. DI PIETRO, Maria Sylvia Zanella. RIBEIRO, Carlos Vinícius Alves (coordenadores). São Paulo: Ed. Atlas, 2010. Manual de Direito administrativo. 22 a ed. Rio de Janeiro: Lumen Juris, 2009.

- CASSAGNE, Juan Carlos. Derecho Administrativo, 6 a ed. Buenos Aires: AbeledoPerrot, 2000.

- CASSESE, Sabino. A Crise do Estado. Tradução: Moreira, Ilse Paschoal e ORTALE, Fernanda Landucci. Campinas-SP: Saberes Editora, 2.010.

- CINTRA, Carlos de Araújo Cintra, GRINOVER, Ada Pellegrini e DINAMARCO, Cândido Rangel. Teoria Geral do Processo. 30ª ed. São Paulo: Malheiros, 2014.

- COELHO, Fábio Ulhoa. Direito e Poder. São Paulo: Saraiva, 2010.

- COUTINHO, Diogo R. O direito nas políticas sociais brasileiras: um estudo sobre o Programa Bolsa Família. In: SCHAPIRO, Mario G.; TRUBEK, David M. (orgs.). Direito e desenvolvimento: um diálogo entre os BRICS. São Paulo: Saraiva, 2012.

- CRETELLA JR. Princípios Informativos do Direito Administrativo. In: Revista do Direito Administrativo. Rio de Janeiro: Fundação Getúlio Vargas. Vol. 93. pp. 1-10. 1968.

- CUNHA, Daniel Antônio. COSTA, João Leonardo e Batista Jr., Onofre Alves. Canais de Participação na Democracia Brasileira. In: MURTA, Antônio Carlos Diniz (org.). Intervenção do Estado e Autonomia Privada - Integração e Sistematização. Belo Horizonte: Arraes Editores, 2013.

- DAHL, Robert Alan. Sobre a Democracia. Trad. UnB. Ed. Universidade de Brasília: Brasília, 2001. 
- DIAS, Maria Tereza Fonseca. Princípio da Supremacia do Interesse Público sobre o Interesse Privado. In: PEREIRA, Flávio Henrique Unes; CAMMAROSANO, Márcio et al. O Direito Administrativo na Jurisprudência do STF e do STJ: Homenagem ao Professor Celso Antônio Bandeira de Mello. Belo Horizonte: Fórum, 2014. p. 399-408.

- DI PIETRO, Maria Sylvia Zanella. Direito Administrativo. 29a ed. Rio de Janeiro: Forense, 2016.

- Discricionariedade Administrativa na Constituição de 1988. $3^{\text {a }}$ ed. São Paulo: Atlas, 2012.

Existe um Novo Direito Administrativo? In : Supremacia do interesse público e outros temas relevantes do direito administrativo. DI PIETRO, Maria Sylvia Zanella. RIBEIRO, Carlos Vinícius Alves (coordenadores). São Paulo: Ed. Atlas, 2010.

O princípio da supremacia do interesse público: sobrevivência diante dos ideais do neoliberalismo. Revista Trimestral de Direito Público. São Paulo: Malheiros, v. 48, p. 63-76, 2004.

Participação Popular na Administração Pública. In: Revista de Direito Administrativo, $\mathrm{n}^{\circ}$ 191, p 26-39 - janeiro a março de 1993. Disponível em: 〈http://bibliotecadigital.fgv.br/ojs/index.php/rda/article/view/45639> Acessado em: 12 abr. 2017.

. "O Direito Administrativo". In: DI PIETRO, Maria Sylvia Zanella e Martins Jr., Wallace Paiva. Tratado de Direito Administrativo Vol 1 - Teoria Geral e Princípios do Direito Administrativo. São Paulo: Revista dos Tribunais, 2014.

. MARTINS JR. Wallace Paiva "Transformações do Direito Administrativo". In: Tratado de Direito Administrativo Vol 1 - Teoria Geral e Princípios do Direito Administrativo. São Paulo: Revista dos Tribunais, 2014.

- DINAMARCO, Cândido Rangel. A Instrumentalidade do Processo. $8^{a}$ edição. São Paulo: Malheiros, 2000. 
- DROMI, Roberto. Sistema Jurídico e Valores Administrativos. Tradução: Equipe Editorial Ciudad Argentina e The TR Company. Porto Alegre: Sérgio Antonio Fabris Editor, 2007.

- DUARTE, David. Procedimentalização, Participação e Fundamentação: para uma concretização do princípio da imparcialidade administrativa como parâmetro decisório. Coimbra: Livraria Almedina, 1996.

- DWORKIN, Ronald. Levando os direitos a sério. Tradução de Nelson Boeira. São Paulo: Martins Fontes. São Paulo, 2002.

- FALLA, Fernando Garrido. Las trasnformaciones del régimen administrativo. $2^{\mathrm{a}}$ ed. Madrid: Instituto de Estudios Políticos, 1962.

- FERRAZ JÚNIOR, Tércio Sampaio. "Interesse Público", São Paulo, 23/08/2011. Disponível em: $\quad$ http://www.terciosampaioferrazjr.com.br/?q=/publicacoescientificas/31> Acesso em 01 nov. 2017.

- FERREIRA, Gustavo Assed. A legitimidade do Estado e a supremacia do interesse público sobre o interesse particular. In: Princípios de Direito Administrativo. MARRARA, Thiago (org.). São Paulo: Atlas, 2012.

- FERREIRA FILHO, Manoel Gonçalves. Princípios Fundamentais do Direito Constitucional. São Paulo: Saraiva, 2009.

- FERRO, Murilo Ruiz. Pontos de convergência entre as teses doutrinárias brasileiras quanto ao princípio da supremacia do interesse público sobre o particular. São Paulo. Faculdade de Direito da Universidade de São Paulo, 170 p.p. Programa de PósGraduação em Direito, São Paulo, 2014.

- FIGUEIREDO, Lúcia Valle. Curso de Direito Administrativo. 9ª Ed. São Paulo: Malheiros, 2008. 
- FIGUEIREDO, Marcelo. Breve Síntese da polêmica em torno do conceito de interesse público e sua supremacia: tese consistente ou devaneios doutrinários. In: Princípios de Direito Administrativo. MARRARA, Thiago (org.). São Paulo: Atlas, 2012.

- FRANÇA, Maria Adelaide de Campos. "Supremacia do Interesse Publico versus Supremacia dos Direitos Individuais. In: Supremacia do Interesse Público e outros temas relevantes do Direito Administrativo. DI PIETRO, Maria Sylvia Zanella e Ribeiro, ALVES, Carlos Vinícius (Org.). São Paulo: Ed. Atlas, 2015.

- FRANÇA, Phillip Gil. Ato Administrativo e Interesse Público: Gestão Pública, controle judicial e consequencialismo administrativo. São Paulo: Editora Revista dos Tribunais, 2013.

- FREITAS, Juarez. O Controle dos atos Administrativos e os Princípios Fundamentais. 5ª edição. São Paulo: Malheiros, 2013.

- GABARDO, Emerson e HACHEM, Daniel Wunder. "O Suposto Caráter Autoritário da Supremacia do Interesse Público e das Origens do Direito Administrativo" In: Supremacia do Interesse Público e outros temas relevantes do Direito Administrativo, (coord.) DI PIETRO, Maria Sylvia Zanella e Ribeiro, Carlos Vinícius Alves. São Paulo: Ed. Atlas, 2010.

- GABARDO, Emerson. Eficiência e Legitimidade do Estado. São Paulo: Ed. Manole, 2003.

- GASPARINI, Diógenes. Direito Administrativo. 7ª ed. São Paulo: Saraiva, 2002.

- GRAU, Eros Roberto. O Direito Posto e o Direito Pressuposto. $7^{\mathrm{a}}$ ed. São Paulo: Malheiros, 2008.

- HABERMAS, Jürgen. A Crise de Legitimidade no Capitalismo Tardio. Tradução de Vamireh Chacon. Rio de Janeiro: Edições Tempo Brasileiro, 1999. 
- HACHEM, Daniel Wunder. Princípio Constitucional da Supremacia do Interesse Público. Belo Horizonte: Editora Fórum, 2011.

- HORA, Marco Aurélio Senko da. A relativização da supremacia do em face do fundamento constitucional da dignidade da pessoa humana. Revista do Tribunal Regional do Trabalho da $9^{\circ}$ Região. Curitiba, v. 36, n. 67, p. 631-657, jul./dez. 2011. Disponível em: <www.trt9.jus.br/internet_base/arquivo_download.do?evento=Baixar..2315593 $>$ acesso em: 08/01/2016.

- IMMERGUT, Ellen M. O núcleo teórico do novo institucionalíssimo. In: Políticas Públicas. SARAIVA, Enrique e FERRAREZI, Elisabete (Org.). Coletânea, volume I, Escola Nacional de Administração Pública, ENAP, 2007. Disponível em: <https://perguntasaopo.files.wordpress.com/2012/02/immergutt002.pdf $>$ Acesso em: 13/04/2016.

- JUSTEN FILHO, Marçal. Curso de Direito Administrativo. $3^{\text {a }}$ ed. São Paulo: Saraiva, 2008.

- KELSEN, Hans. Teoria Pura do Direito. 6 ${ }^{a}$ ed. Tradução de José Cretella Jr. e Agnes Cretella. São Paulo: Editora Revista dos Tribunais, 2009.

- LEAL, Rogério Gesta. Estado, Administração Pública e Sociedade - Novos Paradigmas. Porto Alegre: Livraria do Advogado, 2006.

- LIMA, Gabriel de Araújo. Teoria da Supremacia do interesse público: crise, contradições e incompatibilidade de seus fundamentos com a Constituição Federal. Belo Horizonte: Revista de Direito Administrativo e Constitucional, $\mathrm{n}^{\mathrm{o}}$. 36, p. 123-153, abr/jun. 2009.

- MARQUES NETO, Floriano Peixoto de Azevedo. Regulação Estatal e Interesses Públicos. São Paulo: Malheiros, 2002. 
Interesses públicos e privados na atividade estatal de regulação. In: Princípios de Direito Administrativo. MARRARA, Thiago (org.). São Paulo: Atlas, 2012.

. et al (orgs.). Direito e Administração Pública: Estudos em homenagem a Maria Sylvia Zanella Di Pietro. São Paulo: Atlas, 2013.

- MARTINS JUNIOR, Wallace Paiva. DI PIETRO, Maria Sylvia Zanella (coord.). Tratado de Direito Administrativo - Vol. 1 - Teoria Geral e Princípios do Direito Administrativo. São Paulo: Revistas dos Tribunais, 2014.

- MARRARA, Thiago (org.). Direito Administrativo: Transformações e Tendências, Ed. Almedina. São Paulo, 2014.

- MASSA-ARZABE, Patrícia Helena, Dimensão Jurídica das Políticas Públicas, In: BUCCI, Maria Paula Dallari (Org). Políticas Públicas: reflexões sobre o conceito jurídico. São Paulo: Saraiva, 2006.

- MEDUAR, Odete. A Processualidade no Direito Administrativo. $2^{\mathrm{a}}$ ed. Revista dos Tribunais: São Paulo, 2008.

- Direito Administrativo em Evolução. 2a Ed. Ed. Revista dos Tribunais. São Paulo, 2003.

- MELLO, Shirlei Silmara de Freitas; DANTAS, Roziana G. Camilo Lemos. A lógica do consenso na administração pública contemporânea em face do paradigma do resultado. In: Âmbito Jurídico, Rio Grande, XIII, n. 77, jun 2010. Disponível em: <www.ambitojuridico.com.br/site/index.php?n_link=revista_artigos_leitura\&artigo_id= 7585> Acesso em mar 2017.

- MORAIS, Carlos Blanco de. Manual de Legística: Critérios Científicos e Técnicos para Legislar Melhor. Ed. Verbo, 2007

- MOREIRA NETO, Diogo de Figueiredo. Mutações do Direito Administrativo. $2^{\mathrm{a}}$ ed. Rio de Janeiro: Renovar, 2001. 
. Curso de Direito Administrativo. 16ª ed. Rio de Janeiro: Ed. Forense, 2014.

- Quatro Paradigmas do Direito Administrativo Pós-Moderno. Rio de Janeiro: Forense, 2008.

- Novas Tendências da Democracia: Consenso e Direito Público na Virada do Século - O Caso Brasileiro. In Revista Eletrônica sobre a Reforma do Estado (RERE), Salvador, Instituto Brasileiro de Direito Público, no 13, março/abril/maio de 2008. Disponível em: 〈http://www.direito do estado.com.br/rere.asp > Acesso em: 03 out. 2017.

Para a Compreensão do Direito Pós-Moderno. In: ALMEIDA, Fernando Dias Menezes de Almeida; MARQUES NETO, Floriano de Azevedo; MIGUEL, Luiz Felipe Hadlich. SCHIRATO, Vitor Rhein. (coords.) Direito Público em Evolução - Estudos em homenagem à Professora Odete Medauar. Belo Horizonte: Fórum, 2013, pp. $701 / 714$.

Poder, Direito e Estado: O Direito administrativo em tempos de Globalização. Rio de Janeiro: Fórum, 2011.

- MORENO, Fernando Sainz. Conceptos jurídicos, interpretación y discricionalidad administrativa. Madrid: Civitas, 1976.

- MORETTI, Natália Pasquini. Uma concepção contemporânea do princípio da indisponibilidade do interesse público. In: Princípios de Direito Administrativo. MARRARA, Thiago (org.). São Paulo: Atlas, 2012.

- MOTTA, Paulo Roberto Ferreira. In: BACELLAR FILHO, Romeu Felipe; HACHEM, Daniel Wunder. (coords.). Direito Administrativo e Interesse Público: Estudos em Homenagem ao Professor Celso Antônio Bandeira de Mello. Belo Horizonte: Editora Fórum, 2010.

- MOURA, Emerson Affonso da Costa. Um Fundamento do Regime Administrativo. Rio de Janeiro: Lumen Juris, 2014. 
- MÜLLER, Friedrich. Quem é o Povo? A Questão Fundamental da Democracia. Trad: Peter Naumann. São Paulo: Revista dos Tribunais. $4^{\mathrm{a}}$ ed., 2009.

- NOBRE, Marcos. Participação e Deliberação na Teoria Democrática: Uma introdução. In: COELHO, Vera Schattan P., e NOBRE, Marcos (org.). Participação e Deliberação Teoria Democrática e Experiências Institucionais no Brasil Contemporâneo. São Paulo: Editora 34, 2004.

- NOHARA, Irene Patrícia. Direito Administrativo. 2a ed. São Paulo: Atlas, 2012.

- "Reflexões Críticas Acerca da Tentativa de Desconstrução do Sentido da Supremacia do Interesse Público no Direito Administrativo, In: Supremacia do Interesse Público e outros temas relevantes do Direito Administrativo, org. DI PIETRO, Maria Sylvia Zanella e RIBEIRO, Carlos Vinícius Alves. São Paulo: Ed. Atlas, 2010.

- OLIVEIRA, Gustavo Henrique Justino de. Direito Administrativo Democrático. Belo Horizonte: Editora Fórum, 2010.

. As Audiências Públicas e o processo administrativo brasileiro. Disponível em: <https://www2.senado.leg.br/bdsf/bitstream/handle/id/280/r135-31.pdf?sequence=4> acessado em 15/05/2017.

- OSÓRIO, Fábio Medina. Direito Administrativo Sancionador. $3^{\mathrm{a}}$ ed. São Paulo: Editora Revista dos Tribunais, 2009.

- OSÓRIO, Fabio Medina. Existe uma Supremacia do interesse público sobre o privado no Direito Administrativo Brasileiro?. Revista de Direito Administrativo, Rio de Janeiro, v. 220, p. 69-107, abr/junh. 2000 (reed. mar. 2015). ISSN 2238-5177. Disponível em: http://bibliotecadigital.fgv.br/ojs/index.php/rda/article/view/47527/45222. Acesso em: 15 Mar. 2017. doi:http://dx.doi.org/10.12660/rda.v220.2000.47527. 
- PALMA, Juliana Bonacorsi de. In: ALMEIDA, Fernando Dias Menezes de Almeida; MARQUES NETO, Floriano de Azevedo; MIGUEL, Luiz Felipe Hadlich; SCHIRATO, Vitor Rhein. (coords.) Direito Público em Evolução - Estudos em homenagem à Professora Odete Medauar. Belo Horizonte: Fórum, 2013, PP. 177/201.

- PASSOS, Lídia Helena Ferreira da Costa. Interesse Público: Crítica de sua Legitimidade. São Paulo: Faculdade de Direito da Universidade de São Paulo, 2006. Tese (Doutorado), Departamento de Filosofia e Teoria Geral do Direito - USP/SP, São Paulo, 2006.

- PEREZ, Marcos Augusto. In: Políticas Públicas: reflexões sobre o conceito jurídico. BUCCI, Maria Paula Dallari (org.), São Paulo: Saraiva, 2006.

- REIS, Fábio Wanderley. Deliberação, Interesses e "Sociedade Civil”. In: COELHO, Vera Schattan P., e NOBRE, Marcos (org.). Participação e Deliberação - Teoria Democrática e Experiências Institucionais no Brasil Contemporâneo. São Paulo: Editora 34, 2004.

- RIBEIRO, Carlos Vinícius Alves. Interesse Público: um conceito jurídico determinável. In: Supremacia do Interesse Público e outros temas relevantes do Direito Administrativo. DI PIETRO, Maria Sylvia Zanella e RIBEIRO, Carlos Vinícius Alves (coords.). São Paulo: Ed. Atlas, 2015.

- MORENO, Fernando Sainz. Conceptos jurídicos, interpretación y discricionalidad administrativa. Madrid: Civitas, 1976.

- ROSSI. Giampaolo. Principi di Diritto Amministrativo. 2a ed. Torino: Giappichelli Editore, 2015.

- SANTOS, Boaventura de Souza (org.). Democratizar a Democracia: os caminhos da democracia participativa. Rio de Janeiro: Civilização Brasileira, 2002.

- SARMENTO, Daniel. "Interesses Públicos vs. Interesses Privados na Perspectiva da Teoria e da Filosofia Constitucional”. In: Interesses Públicos versus Interesses Privados: 
Desconstruindo o Princípio de Supremacia do Interesse Público. SARMENTO, Daniel (Org.). Rio de Janeiro: Ed. Lumem Júris, 2007, pp. 23-116.

- SCHIER, Paulo Ricardo. “A 'Supremacia do Interesse Público' no advento do Estado de Direito e na Hermenêutica do Direito Público Contemporâneo" In: Interesses Públicos versus Interesses Privados: Desconstruindo o princípio da supremacia do interesse público. SARMENTO, Daniel (Org.). Rio De Janeiro: Ed. Lúmen Júris, 2005.

. Ensaio sobre a supremacia do interesse público sobre o privado e o regime jurídico dos direitos fundamentais. In: SARMENTO, Daniel (org.). Interesses Públicos versus Interesses Privados: Desconstruindo o Princípio de Supremacia do Interesse Público. Rio de Janeiro: Ed. Lumem Júris, 2005. pp. 219-248.

- SEVERI. Fabiana Cristina. In: Direito e Administração Pública: Estudos em homenagem a Maria Sylvia Zanella Di Pietro. MARQUES NETO, Floriano de Azevedo et al (orgs.). São Paulo: Atlas, 2013.

- SERRANO JÚNIOR. Odoné. Introdução à Contemporânea Teoria dos Direitos Fundamentais. Curitiba: Juruá, 2010.

- SHETH, D. L. In: Democratizar a Democracia: os caminhos da democracia participativa. SANTOS, Boaventura de Souza (org.). Rio de Janeiro: Civilização Brasileira, 2002

- SCHWIND, Rafael Wallbach. Processo Administrativo em Evolução. In: ALMEIDA, Fernando Dias Menezes de Almeida; MARQUES NETO, Floriano de Azevedo; MIGUEL, Luiz Felipe Hadlich; SCHIRATO, Vitor Rhein. (coords.) Direito Público em Evolução - Estudos em homenagem à Professora Odete Medauar. Belo Horizonte: Fórum, 2013. 
- SILVA, Virgílio Afonso da. Na encruzilhada Liberdade-Autoridade - A tensão entre direitos fundamentais e interesses coletivos. In: ALMEIDA, Fernando Dias Menezes de Almeida; MARQUES NETO, Floriano de Azevedo; MIGUEL, Luiz Felipe Hadlich; SCHIRATO, Vitor Rhein. (coords.) Direito Público em Evolução - Estudos em homenagem à Professora Odete Medauar. Belo Horizonte: Fórum, 2013.

Princípios e Regras: Mitos e equívocos acerca de uma distinção. In; Revista latino-Americana de Estudos Constitucionais 1.(2003) p.p. 607/630 - Texto disponível em: $\quad<$ https://constituicao.direito.usp.br/wp-content/uploads/2003-RLAEC01Principios_e regras.pdf $>$ Acesso em: 06 fev. 2017.

- SIRAQUE, Vanderlei. Controle Social da Função Administrativa do Estado. $2^{\mathrm{a}}$ ed. São Paulo: Saraiva, 2009.

- SOARES, Fabiana de Menezes. Legística e Desenvolvimento: A Qualidade da Lei no Quadro da Otimização de Uma Melhor Legislação. In: Caderno Escola Legislativa, Belo Horizonte, v 9, nº 14, p.p. 7-34, jan/dez. 2007.

- SUNDFELD, Carlos Ari. Direito Administrativo Ordenador. $1^{\mathrm{a}}$ ed, $3^{\mathrm{a}}$ tiragem. São Paulo: Malheiros, 2003.

DOMINGOS, Liandro. Supremacia ou Administrocacia no Novo Direito Público Brasileiro? In: ALMEIDA, Fernando Dias Menezes de Almeida; MARQUES NETO, Floriano de Azevedo; MIGUEL, Luiz Felipe Hadlich; SCHIRATO, Vitor Rhein. (coords.) Direito Público em Evolução - Estudos em homenagem à Professora Odete Medauar. Belo Horizonte: Fórum, 2013, pp. 31/38.

- SCHWIND, Rafael Wallbach. In: ALMEIDA, Fernando Dias Menezes de Almeida; MARQUES NETO, Floriano de Azevedo; MIGUEL, Luiz Felipe Hadlich; SCHIRATO, Vitor Rhein. (coords.) Direito Público em Evolução - Estudos em homenagem à Professora Odete Medauar. Belo Horizonte: Fórum, 2013, PP. 375/387. 
- UGARTE, Pedro Salazar. Que Participação para qual democracia?. In: COELHO, Vera Schattan P., e NOBRE, Marcos (org.). Participação e Deliberação - Teoria Democrática e Experiências Institucionais no Brasil Contemporâneo. São Paulo: Editora 34, 2004.

- VITA, Álvaro de. Democracia Deliberativa ou Igualdade de Oportunidades Políticas? In: COELHO, Vera Schattan P., e NOBRE, Marcos (org.). Participação e Deliberação Teoria Democrática e Experiências Institucionais no Brasil Contemporâneo. São Paulo: Editora 34, 2004.

- WERLE, Denílson Luís. Democracia Deliberativa e os Limites da Razão Pública. In: COELHO, Vera Schattan P., e NOBRE, Marcos (org.). Participação e Deliberação Teoria Democrática e Experiências Institucionais no Brasil Contemporâneo. São Paulo: Editora 34, 2004. 